\title{
Sepsis, this Hard, Difficult and Serious Syndrome
}

\section{Edmond Puca*}

Infectious Disease, University Hospital, Albania

Sepsis this syndrome that comes from antiquity until today is independently evolving medical science which remains on the top of the list as a major problem of public health.

The word sepsis is derived from the Greek term rotten or "to make putrid" [1]. It's, defined as the systemic host response to microorganisms in previously sterile tissues. It's a syndrome related to severe infections and is characterized by end-organ dysfunction away from the primary site of infection (Table 1). To meet the definition of sepsis, patients need to satisfy at least two of the Systemic Inflammatory Response Syndrome (SIRS) criteria in association with having a suspected or confirmed infection [1-3].

The SIRS criteria included only fever (or hypothermia), tachycardia, tachypnea, and raised (or decreased) white blood cell count, but the list of possible signs and symptoms is much longer [2,3]. Unfortunately, none of these criteria are really specific. Various candidates have been put forward as potential "markers" of sepsis, but none has enough specificity to qualify as a marker. Especially in recent years the role of inflammation tests are taking very great importance in terms of diagnoses as rapid. However, their use remains always to be discussed in the cost-effective aspect. But again, the role of blood culture remains irreplaceable for many reasons. So the diagnosis of sepsis is difficult, particularly in the ICU where signs of sepsis may be present in the absence of a real infection. However, mortality rates still remain unacceptably high, and it is apparent that much remains to be done to advance our understanding and treatment of this important and increasingly frequent medical problem [2]. It is still one of the most prevalent causes of intensive care units (ICU) morbidity and mortality worldwide $[1,2,4]$.

In one of the large epidemiologic studies of sepsis, published in 2001, Angus et al. [5], estimated a national incidence of 751,000 cases (3.0 per 1,000 population and 2.26 per 100 hospital discharges). In the study by Angus and colleagues, slightly more than half of patients received care in an ICU and the incidence of sepsis in adults increased substantially with age (ranging from 5.3/1,000 for age 60 to 64 years to $26.2 / 1,000$ for age $\geq 85$ years). Overall, mortality was $26.6 \%$ and a substantial increase in mortality was associated with age. In another investigation, the investigators examined the relationship between age and sepsis and showed that when stratifat age 65, the relative risk for sepsis for those older than 65 years was 13.1 times higher than for those younger than 65 years. Overall, individuals $\geq 65$ years of age accounted for $64.9 \%$ of the total cases of sepsis. Interestingly, there were 215,000

Clinical or microbiological evidence of infection along with two out of the four of the following criteria to demonstrate evidence of SIRS:

Temperature $>38^{\circ} \mathrm{C}$ or $<36^{\circ} \mathrm{C}$

Heart rate $>90$ beats $/ \mathrm{min}$

Hyperventilation(respiratory rate $>20$ breaths $/$ min or $\mathrm{PaCO}_{2}<32 \mathrm{~mm} \mathrm{Hg}$

WBC $>12000$ cells $/ \mu \mathrm{L}$ or $<4000$ cells $/ \mu \mathrm{L}$

*Adapted from American Society of Chest Physicians/Society of Critical Care Medicine

Table 1: 1992 ACCP/SCCM Sepsis Definitions*. deaths during the study period, which in fact represented $9.3 \%$ of all deaths in the United States. A subsequent study using a national database demonstrated that the incidence of sepsis increased from the year $1979(0.83 / 1,000)$ to the year $2000(2.4 / 1,000)$ but that there was a slight decrease in mortality from 27.8 to $17.9 \%$ [5]. Based on these studies, it is clear that sepsis is a common disease that appears to be increasing in frequency and that its incidence is clearly associated with increasing age. In reality, these are studies that belong to countries with advanced medicine, but in developing countries or in countries with poor economic resources predisposing factors of sepsis are entirely different. However, most of development countries do not have comprehensive studies, so physicians should propagate more on this important syndrome with the only purpose of evaluation. While the burden of sepsis is extreme throughout the world, the difference in resources available to patients with sepsis is even more extreme.

The recent Sepsis occurrence in Acutely Ill Patients (SOAP) study across Europe reported that more than $35 \%$ of intensive care unit (ICU) patients had sepsis at some point during their ICU stay, with a mortality rate of $27 \%$ [2].

Nevertheless, although the risk of death per individual case may be falling, the overall number of patients dying from sepsis mortality rates is growing as more patients are affected [2].

Age participates in modifying the host response to sepsis, as infections in neonates, children, and adults may be quite different. Past history is another feature, as patients with particular co morbidities (e.g., cirrhosis, mellitus diabetes etc) or receiving immunosuppressive drugs may have different characteristics. Genetic factors likely play an important role in determining who develops sepsis, as well as its severity, and also modulate the response to treatment [2].

The increased incidence of sepsis was thought to be related to the increased prevalence of patients with HIV/AIDS, community-acquired or intra hospital infections, puerperal sepsis in poor countries, increased patients with invasive procedures, malignant diseases and the use of immunosuppressive drugs.

So based on this perspective, sepsis is an inclusive disease. It occurs to children, adults, elderly people, in all branches of medicine and it's in the top list of diagnoses for higher mortality. Sepsis remains to be a significant cause of morbidity in hospitalized patients worldwide. Septic shock is the most common type of shock encountered by physicians

*Corresponding author: Edmond Puca, Infectious Disease, University Hospital, Albania,E-mail: edmond_puca@yahoo.com

Received January 08, 2013; Accepted January 08, 2013; Published January 11 2013

Citation: Puca E (2013) Sepsis, this Hard, Difficult and Serious Syndrome. Clin Microbial 2: e105. doi:10.4172/2327-5073.1000e105

Copyright: (c) 2013 Puca E. This is an open-access article distributed under the terms of the Creative Commons Attribution License, which permits unrestricted use, distribution, and reproduction in any medium, provided the original author and source are credited. 
and sepsis has been reported as the most common cause of death in non-coronary intensive care units.

Prevention, early diagnosis, timely and appropriate pharmacologic intervention, identification of poor prognostic features and aggressive care for those with such features are ways by which the management of sepsis can be improved.

In this editorial, I want to emphasize that sepsis is a syndrome that occurs in every medical specialty, in every age, every day. Even his treatment is being done more difficult every day due to resistant pathogens. Therefore we as doctors need to find the first, the best and the fastest solution for its prevention and treatment.

\section{References}

1. Silva E, Passos RDH, Ferri MB, Poli de Figueiredo LF (2008) Sepsis: from bench to bedside. Clinics $63 ; 109-120$.

2. Vincent JL, Abraham E (2006) The last 100 years of sepsis. Am J Resp Crit Care Med173: 256-263.

3. Levy MM, Fink MP, Marshall JC, Abraham E, Angus D, et al. (2003) 2001 SCCM/ESICM/ACCP/ATS/SIS International Sepsis Definitions Conference. Crit Care Med 31: 1250-1256.

4. Angus D, Pereira C, Silva E (2006) Epidemiology of severe sepsis around the world. Curr Drug Targets Immune Endocr Metabol 6: 7-16.

5. Angus DC, Linde-Zwirble WT, Lidicker J, Clermont G, Carcillo J, et al. (2001) Epidemiology of severe sepsis in the United States: analysis of incidence, outcome, and associated costs of care. Crit Care Med 29: 1303-1310. 